\title{
ENACTING DYNAMIC DISTRIBUTION NETWORKS - THE DAMASCOS PROJECT
}

\author{
Thomas Goletz ${ }^{1}$, J. J. Pinto Ferreira ${ }^{2}$ \\ ${ }^{1}$ INTERFACE GmbH, Nuremberg, Germany,tg@iface.de \\ ${ }^{2}$ INESC Porto, Rua José Falcão 110, Porto, Portugal, jjpf@fe.up.pt
}

\begin{abstract}
This paper presents the DAMASCOS (Dynamic Forecast for Master Production Planning with stock and capacity constraints) IST-1999-11850 project'. It is the DAMASCOS objective to design and develop an open platform providing adequate IT modules and mechanisms in order to manage Customised Supply Networks while integrating consumer and its demands. In this context, key objectives are the usage of a workflow model driven approach to support development of a new organisational scheme enabling a flexible/efficient co-operation inside the supply network. This will enable the establishment of a new kind of consumer-supplier relationship, built on lean, flexible and innovative functional modules for production order management, distribution/stock management, sales management and demand calculation. The DAMASCOS system also features integrated forecasting as a basic functionality. State-of-the-art information technology will enable inter-enterprise integration based on de jure or de facto standards such as TCP/IP, CORBA, DCOM, etc., fostering a strong market/customer orientation.
\end{abstract}

\section{INNOVATION ON DISTRIBUTION NETWORKS}

\section{The innovative approach for the supply network and the principal producer}

The principal producer is an information node flipping information between its suppliers and its many retailers, triggered by consumers. At the supplier site the sources of supply explode, thus managing information becomes increasingly complex. Many valuable information resides in people's heads, i.e. what kind of attitude does the owner have or is there a good co-operation? Such information, which has to be captured and evaluated, is an important input for the supply network management, since for each order to be processed, the supply network will be customised to the best supply chain to fulfil that order. New requirements exist at the distribution and sales site due to the need of flexibility in the product provision, which have a direct and strong impact to activities in the supply network. Consumer demands are the basic value for these requirements. Each sales transaction initiates activities in the supply network. Direct and indirect relations between consumer demands and sales activities exist, i.e. marketing and advertising activities influence consumer demands. Because sales transaction is a fundamental transaction for a successful business, the

\footnotetext{
${ }^{1}$ DAMASCOS Partners: INESC Porto - project coordination (PT), INTERFACE (DE), SMD/PARAREDE (PT), SICS (SE), NMA (SE), ATECA (IT), KYAIA (PT)
} 
supply network management needs a strong support tool for forecasting future sales by considering the relations inside the supply network. Actual market surveys have confirmed that there are significant inefficiencies in the supply network processes and that there is the potential for more integrated and consumer oriented processes in which consumer needs are met, economical losses are significantly reduced and both quality and efficiency is improved. The rationale behind the development of such an integrated approach is that the efficiency of supply network is presently constrained by the inaccurate or false input information both from the market and from the supplier sites. This situation reflects the fragmented structure of the supplier and retail industry and particularly the isolated position of the consumer in the supply network. The proposed approach enables principal producers' co-operation with all other partners in the supply network and that for each production order a customised supply chain will be created. This means also, that the integration of suppliers/sub-suppliers has to be re-engineered. DAMASCOS project will provide a "lean" supply chain management system, integrating independent and external partners at retail site and at supplier site, and will help them to co-operate in an efficient way. The co-operative planning, forecasting and replenishment will be the next great advance in inventory and customer relationships and a competitive advantage for those organisations that are first to implement it widely.

\section{A Vision for Supporting Business process modelling and enactment}

To improve competitiveness, supply network management requires software support to help managing complex, dynamic and often less structured environment that characterises the supply network operations. This has been supported so far in a number of different ways, but mainly through specific developments leading to expensive tailor made solutions, or through standard packages that do not always fulfil adequately the end user requirements. The cornerstones between Enterprise Modelling and Enterprise Integration are reference models and libraries of the so-called functional operations. Functional operations are units of functionality. On one hand, they represent the lowest level of abstraction from the business user viewpoint in developing his/her application (i.e. elementary actions of enterprise activities in the enterprise model). On the other hand, they are basic primitives or commands offered by functional entities (i.e. machines, software applications or human actions) making up the integrated system. These functional operations use or process enterprise objects as arguments (material or information objects). These objects are passed from one application to another in the activity chain (or workflow) governing the logic of the execution of the business processes to be integrated. The need for a coordination mechanism is therefore clear and will be played by the so-called workflow management system.

\section{A Vision for IT support to co-ordination and software function development}

The information integration and distribution is achieved by using existing "standards" such as CORBA, DCOM, or e-mail for lighter solutions. This backbone is used to plug-in as needed to existing modules. DAMASCOS has information server modules hiding the underlying complexity of existing systems, and providing the 
functions required for support business process execution. Next, we have clients to those business applications to be accessed either in an internet-browser environment or as standalone applications. Our business process model-oriented approach to business solutions foresees the existence of a workflow management system. A special client/serve module will have to be plugged-in to foster two way communication between the WFMS engine and remote WMFS interfaces implementing a to-do list interface either on a browser environment or as a standalone application.

\section{A Vision for forecasting in the supply networks}

An important component in the system is the ability to predict the flow of products through the supply network, and use this information to avoid large stocks, or big delays in delivery. The central issue is to predict the future sales of the product. There are several factors that may affect the sales, and which must be considered in addition to the history of previous sales. Most notable are perhaps factors like advertisements and campaigns, but also weather, trends, and the emergence of competing products may have substantial impact. The advertisement factor plays a very special role in the forecasting system, since it provides a feedback loop to the system. It is clear that sales are affected by advertisements, but that also means the type and amount of advertisement is adjusted in response to the recent sales. Thus it is important to consider the whole picture of this interaction. The feedback in the system poses specific problems that must be dealt with in the forecasting, but it also gives large opportunities for exploitation. It is not only the expected sales volume that is important, but also an indication of the certainty of the prediction, indicated e.g. as an error bar, a variance, or a probability distribution of the expected sales. This enables, e.g., the manufacturer to have larger margins in the stock supply in a period with high volatility than in periods when sales can be more accurately predicted. It is therefore important to include certainty analysis in the system.

\section{THE EXTENDED ENTERPRISE SCENARIO FOR THE DYNAMIC SUPPLY NETWORKED ORGANISATION}

The illustrated scenario presents as a part of the supply network two nodes of the distribution network, the actual production node (principal producer), and one distribution node. On top, we have the distribution business process chain, further refined to describe network node activities. In this case, activities $\mathrm{A}, \mathrm{B}$ and $\mathrm{C}$ are performed at production warehouse, and D, E and F are executed at the distribution node warehouse. As a result of this approach, and of the model-driven workflow co-ordination, at each point in time, operators are provided with the access to the required business functions in a particular workflow activity context. In A, for example, the user is presented a screen to assign articles to customers, whereas in the second activity, the user asked to perform the actual packing list. The business process extension is in this case achieved by allowing shipping information to be sent to the corresponding distributor. This business process extension allows therefore for the early distributor notification that a particular shipment was made. Upon truck arrival at the distributor node, the received articles are checked against expected orders, and the process goes on inside distributors node. 


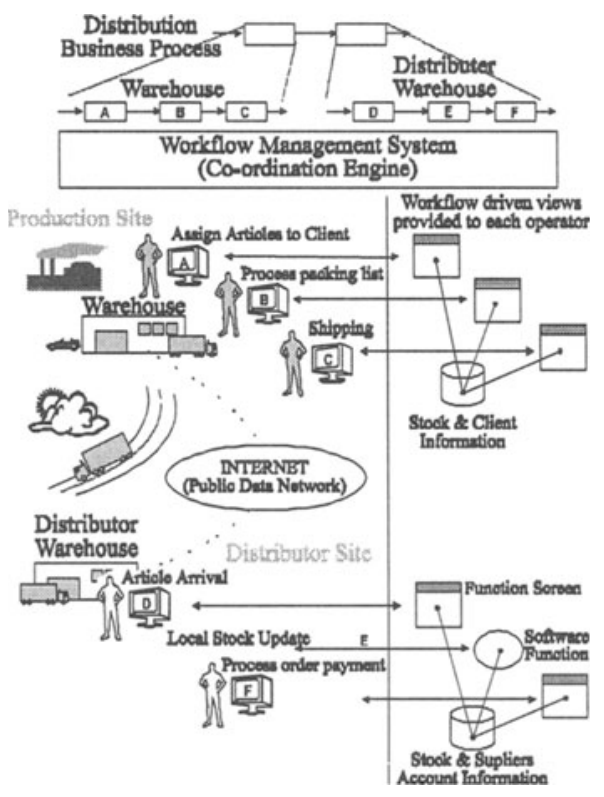

Figure 1: The distribution process co-ordinated by FFMS

\section{DAMASCOS PROJECT OVERVIEW}

\section{Introduction}

The overall vision of the project focus on the development of a product built of modular modules that will be used to improve planning in the supply network from customer to production. The aim of the project is, to have at the end not only simple prototypes but also a clear path for further development of prototypes into industrial products capable of being distributed in different branches and countries.

\section{Information Technology Approach Rationale}

As illustrated, the project specifies a model-based approach to the construction of the networked organisation IT infrastructure. To this end, we defined an iterative approach to the derivation of typical enterprise activities and functional entities capable of supporting the actual workflow execution during the enterprise daily operation. The usage of activity templates (Partial models), will greatly facilitiate the construction of custom business process distribution models, moreover, it will facilitate the actual model sharing by the DAMASCOS forecast module, using the distribution network model in supporting the actual forecast results usage.

The identification of the involved functional entities performing the business functions is indeed the integration success factor. We will have two types of functional 
entities, the human individual or organisational unit, or the so-called software business functions (sales and distribution functions) supported by adequate business information servers. This division further allows a systematic approach to the construction of the enterprise information services functional and information models (Distributed Info. Model), to be supported by distributed enterprise information servers (e.g. legacy systems such as existing databases and/or ERP).

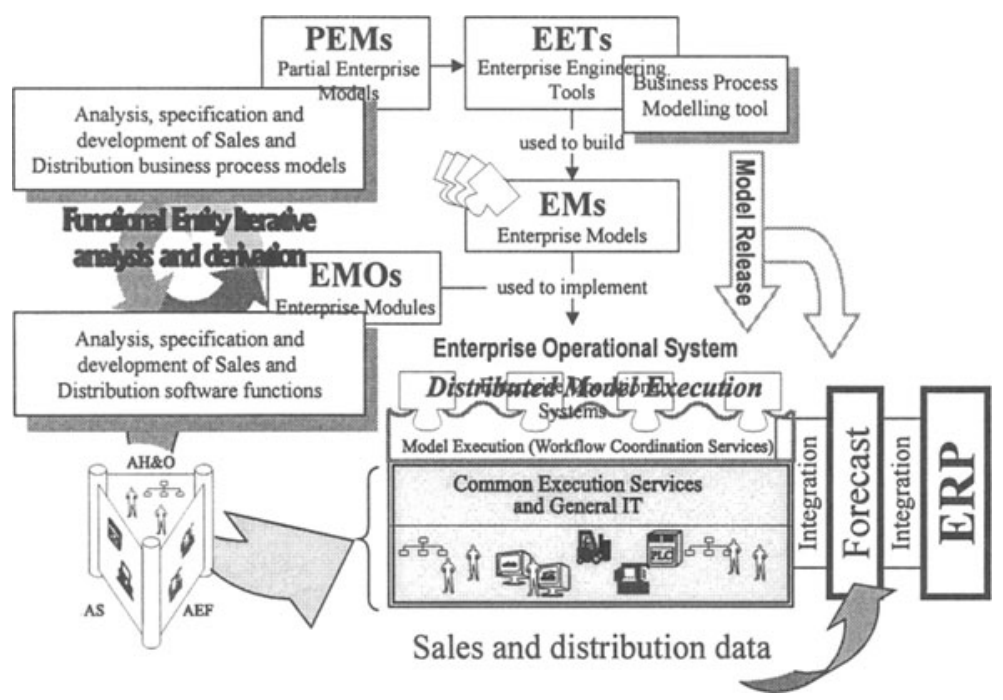

Figure 2: The Information Technology approach rationale

\section{DAMASCOS Architecture}

The architecture of the DAMASCOS system brings together state-of-the-art technology components, namely work flow co-ordination and Internet technologies, to allow companies to focus their business activities to the needs of their customers. The integrated approach along all levels of the supply chain will avoid low level integration between several function modules and enforce the overall co-operation and transparency. Basic methodologies / concepts used to achieve the DAMASCOS project objectives are:

- Extended Enterprise Integration

Integration to principal producer, its suppliers and retailers along supply chain

- Module oriented conception

DAMASCOS suite contains of several software modules

- Usability

Simple usage by adequate user interface and consistent look $\&$ feel

- Forecast

Integration of forecasting in a supply network for better driving the entire chain 
- Collaboration and co-ordination

Model-based approach, driven by work flow management systems, for a new kind of co-operation in the supply network, looked at as an extended enterprise

- Internet Collaboration

Internet/intranet, CORBA, DCOM as basics for the extended enterprise business integration communication

\section{DAMASCOS Suite}

To achieve its objectives, DAMASCOS we will its effort in the specification and development of the following main modules (figure 3 - DAMASCOS suite):

- Workflow Backbone

All activities in the supply network and their sequence and dependencies will be co-ordinated by a WMFS system, either central or distributed, according to the system architecture to be specified in the early months of the project. To this end, the Workflow Backbone will provide the integration between existing WFMS and DAMASCOS workflow clients (considered as part of the distributed backbone), supported by a CORBA/COM based distributed infrastructure over the Internet. In the course of this development task, we will build on general requirements for distributed systems such as interoperability, scalability, security, and so forth, and concentrate on the actual problem domain issues such as limited communication bandwidth for particular pilot site-nodes. DAMAS$\mathrm{COS}$ aims at being as independent as possible from the selected workflow management tool. This should be achieved provided that an API is provided allowing the external WMFS integration with the DAMASCOS infrastructure backbone. On the other hand, we will have to keep in mind the need for sharing the workflow model (distribution model) with the Forecast module.

- SALSA

SALSA will be used by sales people, independent from their locations, as well as by decentralized structured organisations in order to exchange informations like customer or sales data as well as order or market data in reference to the entire supply chain. SALSA integrates external workers in the information and communication infrastructure of the supply chain. This enables the gathering of all needed information from the customer resp. market, which can not be provided by using new eCommerce channels. The ultimate objective of the usage of SALSA is the management of the customer relationship from the point of view of sales by considering supply chain requirements. SALSA integrates therefore the traditional organized sales structures, which have the majority in the business world today, to the world of the new eCommerce business solutions like Supply Chain Management.

- IDLS - Integrated Distribution and Logistics Support System

The overall scope of DAMASCOS covers the flow of goods from supplier through manufacturing and distribution chains to the customer and finally to the consumer. The approach is to maximise profit by enhancing competitiveness in the consumer market. This will be achieved by providing the right product at the 
right location in the shortest time possible by lowest cost. The entire supply chain has to be co-ordinated efficiently, by i.e. minimising total channel inventories, eliminating constraints, compressing time frames and avoiding quality problems. Starting from the customer, the distribution functionalities of the supply chain will be support by the IDLS. The IDLS will manage the inventory data of all level inside the supply chain. Based in these information and the input data about planned production orders, IDLS will support the management of the distribution processes.

- IPO - Interface to Production Order management

The overall scope of DAMASCOS the integration of the production planning is most essential. Starting from the input information from forecasting and IDLS the module IPO will calculate needed quantities for single items. These quantities will be sent to the production order management as a kind of order. Vice versa IPO will receive the information about the planning for production. IPO is therefore an integration tool to exchange information between the add-on DAMASCOS suite and existing MRP/ERP systems.

- $\mathrm{D}_{3} \mathrm{~S}_{2}$ - Forecast Module

Forecast is definitely a key requirement to be assist the supply chain management (SCM), as well as for management of sales, production and distribution network. It is an objective to support the SCM input with adequate forecast information based on real sales and distribution data. The forecasting module can be used as a separate module to simulate reactions of the market to certain impacts. This will allow the assessment of different marketing strategies by simulating the future development based in the detailed current situation. The DAMASCOS forecast module integrates also the ideas of brand tracking, which is a high sophisticated tool for evaluating advertising efforts.

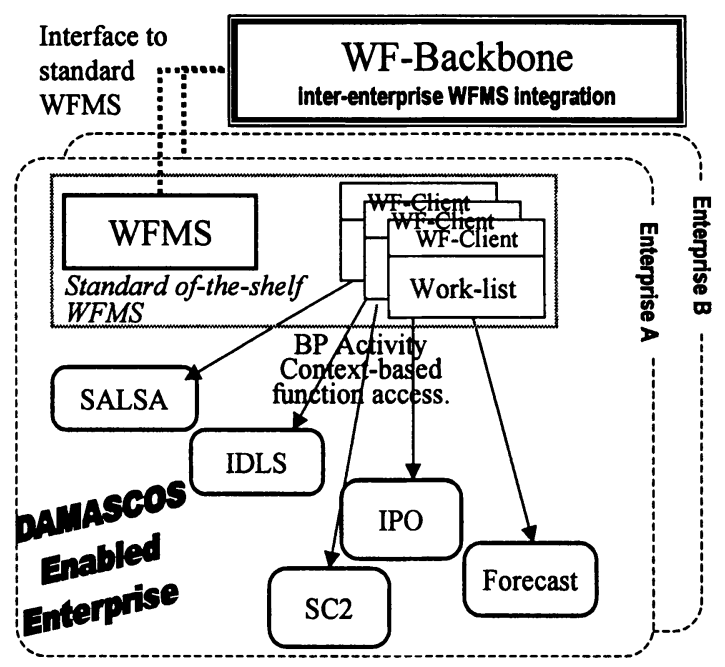

Figure 3 - DAMASCOS Suite 


\section{CONCLUSIONS}

DAMASCOS addresses the need to increase the competitiveness of SME's by providing a conception as well as a system to manage the supply network itself and its order-related customisation. DAMASCOS further enforces a consumer oriented consumer-supplier relationship by integrating consumer demands into supply network by using existing distribution and sales channels. In this context, DAMASCOS focuses directly to the consumer goods industries, covering therefore several SME's at all levels of the supply chain. This is specially true in the retail and supply levels, which are most important for the employment situation in Europe. The industries of the pilot users employ more than 8 Mio. people and the most important role in these industries will be played by SME's. During the last years the situation of the retail business changed dramatically. Sales to the consumer, especially in clothing industry, are stagnating or going down. The profits became very small. The consumer requires apart from the product as such, further services, which cannot be offered by the retail business due to its structure. In order to solve this problem each partner in the network tried to optimise his economical situation by reducing costs and moving tasks to other partners in the supply chain without integrating the business processes. This is indeed the strong point for DAMASCOS providing a conception to integrate independent partners into the supply chain of the principal producers as well as a system to manage production orders depending from consumer demand and supplier situation. In the DAMASCOS scenario a principal producer will manage its supply network, containing many independent companies, as if the customised supply network is one enterprise. One of the key aspects of DAMASCOS is the usage of the retailers as the interface to the market by extending retailers capabilities through integration.

The DAMASCOS concept is not only internet-based and driven by the eBusiness or eCommerce hype. Moreover, DAMASCOS fosters the usage of these concepts by SMEs enabling its realisation customised to each particular company business conception - based both on research and on practical experiences - and at least by supporting the competitive edges of its users.

\section{References}

[Fiddis, C. 1998] Fiddis, C., 1998, Managing Knowledge in the Supply Chain. The key to Competitive Advantage. Financial Times Business Ltd. 1998

[Fine, C. 1998] Fine, C., 1998, Clockspeed: Winning Industry Control in the Age of Temporary Advantage. Perseus Books 1998

[Vernadat' 96] Vernadat, François B., 1996. Enterprise modelling and integration: principles and applications, (Chapman\&Hall, London, ISBN 041260550 3).

[GERAM] IFIP-IFAC Task Force, 1997. Generalised Enterprise Reference Architecture and Methodology - GERAM, Version 1.5, 1997-09-27.

[CEN Report 1832:1995] CEN Report/TC 310, 1995. CIM Systems Architecture- Enterprise model execution and integration services (EMEIS)"-"Annex E: CIMOSA 's Framework for integrating Infrastructure. CR 1832:1995, Feb.

[CIMOSA] ESPRIT Consortium AMICE, 1996. CIMOSA - Open System Architecture for CIM, Technical base line version 3.2 . 